\title{
The Meta-Analysis on the Effect of Emotion on Rational Person Behavior in the Decision Neuroscience Perspective
}

\author{
Guoqiang Xiong*, Yuxi Liu and Xi Liu \\ College of Economics and Management, Xi'an University of Technology, Xi'an, 710054, China
}

\begin{abstract}
Nowadays, the research on the effect of emotion on rational person behavior is a problem of concern in the field of desicion science, and it is a forward direction to carry out the relevant research using the method of decision neuroscience. In this paper, we use the method of meta-analysis to analyze 30 effect values which were extracted from 19 literatures. The result shows that emotion has a significant influence on rational person behavior. At the same time, we exploratory find that emotional valence has a significant positive effect on the relationship between the two. Positive emotions can lead rational person to take risk seeking behavior in risk decision making or cooperative behavior in social decision making; Negative emotions can lead rational person to take risk-averse behavior in risk decision making or non cooperative behavior in social decisions. The influence of positive or negative emotions on rational person behavior are reflected in the amplitude differences of brain electrical components such as P2, P3, N2, ERN, MFN and FRN, but there is no consistent conclusion of amplitude change direction for various brain electrical components. This result gives the relationship between emotion and rational person behavior, and puts forward the direction of future research.
\end{abstract}

Keywords: Behavior model, decision neuroscience, decision science, emotion, meta-analysis.

\section{INTRODUCTION}

Rational person, also known as the "rational person hypothesis" which assumes people are rational thinking or behavior and strive for the economic benefits. There is no denying that emotion is accompanied by rational person in decision making. In other words, rational person always act accordingly to a certain emotional state.

By reviewing literatures, we find researches about the effect of emotion on behavior mainly focused on two aspects, one is whether there is emotional impact on behavior, the other one is the result of emotional impact on behavior. A large number of empirical studies had found that rational person behavior affected significantly by emotion. In the decision-making behavior, emotion can serve as an active information input or an important predictor. More importantly, emotion help improve the quality and effectiveness of decision-making behavior [1-6]. Although the research about the effect of emotion on rational person behavior are quite fruitful, but most of them research from the perspective of traditional behavior science, for this reason they cannot fundamental explain some phenomena existing in the rational person behavior. In this context, it is necessary to explore the mechanism of rational person behavior under the influence of emotion by using the methods of neuroscience like nerve imaging (FMRI, ERP, etc.) from the perspective of decision neuroscience [7]. Among them, decision neuroscience mainly by means of brain imaging techniques, psychology and decision science to explore rational person how to make decisions from the aspects of neuroscience [8].
Despite scholars carried out some related experimental study on emotion and rational person behaviors by means of modern neuroscience, which accumulated a lot of empirical research results. But at present, there is not a systematic summary and quantitative evaluation of the existing literature. Moreover, numerous studies independently investigated the effect of single emotion dimension on rational person behavior, but lack of analyze, summarize and explain these different results. Therefore, based on the shortcomings and deficiencies of existing literatures, we use the method of meta-analysis to analyze 30 effect values from the perspective of neuroscience decisions. These effect values are extracted from 19 literatures which published on domestic and foreign academic journals from 2003 to 2012. Therefore, we achieve a scientific summary from individual studies to general conclusions, and reveal the influence of emotion on rational person behavior more systematically and quantitatively. At the same time, we find that the influence of emotional valence, emotional state, types of decisions and types were tested may impact the relationship between emotion and behavior from the perspective of the regulated variable, and analyze the fundamental reasons for different conclusions. Conclusions of this study help us correctly grasp the influence of emotion on decision behavior in practice, and enrich the field of emotion research and decision-making behavior.

\section{SAMPLES AND DATA}

This paper use method of the meta-analysis to integrate existing neuroscience experiment results of emotion and behavior, and then analysis from the following three questions: (1) If rational person behavior affected by emotion. (2) What factors regulate the emotion impact on the rational 
Table 1. The list of literatures that is used to meta-analysis.

\begin{tabular}{|c|c|c|c|c|c|}
\hline No. & Literature & Sample Size & Control Group & The Dependent Variable & $\begin{array}{l}\text { Effect Value } \\
\quad(d)\end{array}$ \\
\hline 1 & Baba Shiv. et al. (2005) [10] & 34 & Normal group/ Brain injury group & Risk-seeking & -0.588 \\
\hline 2 & Baba Shiv. et al. (2005) & 22 & Control group/ Brain injury group & Risk-seeking & -0.526 \\
\hline 3 & Knutson Wimme (2008) [11] & 15 & Positive/ Neutral & Risk-seeking & 0.464 \\
\hline 4 & Knutson Wimme (2008) & 15 & Negative/Neutral & Risk-seeking & 0.081 \\
\hline 5 & Liangchao Shu (Experiment 4) (2009) [12] & 17 & Positive/ Neutral & Risk-seeking & 0.567 \\
\hline 6 & Liangchao Shu (Experiment 4) (2009) & 17 & Negative (fear)/Neutral & Risk-seeking & -0.104 \\
\hline 7 & Liangchao Shu (Experiment 4) (2009) & 17 & Positive/ Neutral & Risk-seeking & 0.444 \\
\hline 8 & Liangchao Shu (Experiment 4) (2009) & 17 & Negative (fear)/Neutral & Risk-seeking & -0.062 \\
\hline 9 & Kai Wang (Experiment 4) (2010) [13] & 25 & Negative/neutral & Risk-seeking & -0.630 \\
\hline 10 & Julie L. Hall. et al. (2) (2010) [14] & 24 & Happy/Neutral & Risk-seeking & 0.67 \\
\hline 11 & Julie L. Hall. et al. (2) (2010) & 24 & Angry/ Neutral & Risk-seeking & -0.16 \\
\hline 12 & Martin P. Paulus. et al. (2003) [15] & 17 & Positive expectations & Risk-seeking & 0.556 \\
\hline 13 & Shiv. et al. (2005) [16] & 41 & Normal group/ Brain injury group & Risk-seeking & -0.581 \\
\hline 14 & Shiv. et al. (2005) & 44 & Normal group/Drug addicts group & Risk-seeking & -0.529 \\
\hline 15 & Giorigio. et al. (2005) [17] & 15 & Disappointment & Risk-seeking & 0.081 \\
\hline 16 & Giorigio. et al. (2005) & 15 & regret & Risk-seeking & 0.214 \\
\hline 17 & Bechara (1999) [18] & 9 & Normal group/Brain injury group & Risk-seeking & 0.556 \\
\hline 18 & MAS Boksem, D De Cremer [19] & 20 & Hate & Unfair distribution of choice & 1.066 \\
\hline 19 & Sanfey. et al. (2003) [20] & 19 & Hate & Unfair distribution of choice & -1.329 \\
\hline 20 & Michael Koenigs. et al. (2007) [21] & 21 & Normal group/Brain injury group & Unfair distribution of choice & -0.530 \\
\hline 21 & Michael Koenigs. et al. (2007) & 21 & Control group/Brain injury group & Unfair distribution of choice & -0.632 \\
\hline 22 & David Polezzi. et al. (2008) [22] & 13 & Hate & Unfair distribution of choice & -1.678 \\
\hline 23 & Thomas Schreiner. et al. (2009) [23] & 30 & Happy/Angry & Unfair distribution of choice & 0.220 \\
\hline 24 & Jun Zhong (2009) [24] & 14 & $\begin{array}{l}\text { Positive expectations/ } \\
\text { Negative expectations }\end{array}$ & $\begin{array}{c}\text { Cooperative behavior in the } \\
\text { trust game }\end{array}$ & 0.451 \\
\hline 25 & Hewig J. et al. (2011) [25] & 12 & Negative emotion & Unfair distribution of choice & -1.402 \\
\hline 26 & Jue Wang (Experiment 1) (2012) [26] & 15 & Negative/Positive & Unfair distribution of choice & 0.166 \\
\hline 27 & Jue Wang (Experiment 3) (2012) & 17 & Hate/Neutral & $\begin{array}{l}\text { Acceptance rate of unfair dis- } \\
\text { tribution }\end{array}$ & -0.029 \\
\hline 28 & Katia M. Harlé. et al. (2012) [27] & 19 & Sadness /Neutral & $\begin{array}{l}\text { Acceptance rate of unfair dis- } \\
\text { tribution }\end{array}$ & -0.483 \\
\hline 29 & María I. et al. (2012) [28] & 45 & Angry/Neutral & $\begin{array}{c}\text { Cooperative behavior in the } \\
\text { trust game }\end{array}$ & -0.503 \\
\hline 30 & María I. et al. (2012) & 45 & Excited/Neutral & $\begin{array}{c}\text { Cooperative behavior in the } \\
\text { trust game }\end{array}$ & 0.171 \\
\hline
\end{tabular}

person behavior? (3) Explain why would these factors regulate the relationship between the two from the perspective of neuroscience?
In order to explore above issues, this paper select samples according to the following four criteria: (1) Individual studies must studied emotion and behavior from the perspec- 
Table 2. The result of meta-analysis

\begin{tabular}{|c|c|c|c|c|}
\hline The Number of Study & Sample Size & The Average Effect Value & $\mathbf{9 5 \%}$ Confidence Interval & $Q(\mathbf{n}-\mathbf{1})$ \\
\hline \hline 30 & 656 & -0.166 & $(-0.319,-0.01)$ & 48.212 \\
\hline
\end{tabular}

tive of decision neuroscience. In addition, empirical analysis uses the methods of decision neuroscience. (2) Individual studies are needed to provide sample size and statistical values related with the calculation of effect value (such us the mean, standard deviation or $r, t, F$ ). (3) Independent variable of the sample must be linked to emotion. (4) Dependent variable of the sample must contain behavior.

In order to get sample literatures needed for the study, we searched the database of Chinese and English. The key words include: emotion, happy, excited, sadness, angry, fear, decision-making, behavior and decision neuroscience etc. We retrieved CNKI database, Chinese Scientific Journals database, Wan Fang database, EISEVIER Science Direct, IEEE, ISI Web of Science (SCIE, SSCI, ISTP, ISSHP), Springer Link database and Google academic database, and found that there are 19 articles meet the requirements of sample literatures. After filtering out the required research literature and through statistical calculation, we got 30 standardized effect values (see Table 1). According to mathematical statistics knowledge and research experience of predecessors, when we use the method of meta-analysis, the effect size (sample size) had better not less than 30 , because the results would be more accurate, and if the number are 50 or more, the result is better [9]. It can be seen that, in this paper the amount of effect size (30) meet the basic requirement of meta-analysis.

\section{META-ANALYSIS}

Meta-analysis is based on the evaluation of the effect size between the two variables (here is the emotion and rational person behavior). The common index of effect size is $d$, which does not depend on the sample size. This index

can reflect the correlation between the independent variable and the dependent variable, and have a certain link to the significance test (such as $t, F, \chi^{2}$ test etc.) of null hypothesis.

If the result shows a trend, the effect values towards a certain direction. Effect value is calculated as follow:

$$
\begin{aligned}
& d_{i}=\frac{\left(\bar{X}_{1 i}-\bar{X}_{2 i}\right)}{S_{i}} \\
& S_{i}=\sqrt{\frac{\left(n_{1 i}-1\right) S_{1 i}^{2}+\left(n_{2 i}-1\right) S_{2 i}^{2}}{n_{1 i}+n_{2 i}-2}}
\end{aligned}
$$

Among, $\bar{X}_{1 i}, \bar{X}_{2 i}$ respectively represents sample means of the No. $i$ study, $S_{i}$ is the combined standard deviation of two samples. In general, most of the sample literatures are not directly provide corresponding mean and standard deviation, and they only give part of statistics ( $r, t, F, \chi^{2}$ test etc.). At this time, we must convert the formula between statistics to get the desired effect value. By calculating the index data, the effect value $d_{i}$ of each experimental study is shown in Table 1.

After obtaining the effect values which come from each study of emotional impact on the rational person behavior, we can use (3) to calculate the average effect value of the total sample $d$.

$$
\bar{d}=\frac{\sum_{i=1}^{k} w_{i} d_{i}}{\sum_{i=1}^{k} w_{i}}
$$

Among them, $\omega_{i}=2 N / 8+d_{i}^{2}, \mathrm{~N}$ is the sample size of each study. Since the sample size in each study is different, the precision of individual effect values are also differ. So we weighted sample size of each study and calculate $95 \%$ confidence interval of the $\bar{d}$ :

$$
\begin{aligned}
& \bar{d} \pm 1.96 \frac{S_{e}}{\sqrt{k}} \\
& S_{e}=\left[4 k / \sum_{i=1}^{k} N_{i} \times\left(1+\bar{d}^{2} / 8\right)\right]^{1 / 2}
\end{aligned}
$$

If the value 0 is not included in the $95 \%$ range, it indicates that the average effect value is notable, that is to say the emotion significantly impact on rational person behavior.

\subsection{Homogeneity Test}

Homogeneity test is the basis of comprehensive analysis. It can test whether there is a consistency between each study, which is the premise of weighted multiple statistics. When conducting homogeneity test, we often use the Q statistics of the total sample.

$$
Q=\sum_{i=1}^{k} w_{i}\left(d_{i}-\bar{d}\right)^{2}
$$

According to the above formula we calculate the $Q$ statistics of the total sample as well as the average effect value of the total sample and its $95 \%$ confidence interval, as shown in Table 2.

Since $Q$ value obey to $\chi^{2}$ distribution and $d f=k-1$. The statistics can be compared with $\chi^{2}(0.05, k-1)$, and then determine whether to reject $H_{0}$, among, $H_{0}: d_{1}=d_{2}=\cdots=d_{i}$. If we reject $H_{0}$, it is indicated that each study is heterogeneous, there may be other factors that regulate the emotion impact on the rational person behavior [29]. The $Q$ value of total sample in this paper is $Q$ $>\chi^{2}(0.0529)=42.557$. So the hypothesis of homogeneity is 
not established, indicating each study exist the heterogeneity, and existing regulated variables which may regulate emotion to rational person behavior.

\subsection{Analysis of Results}

Table 2 presents a meta-analysis result of the emotion impact on the rational person behavior. You can see that the average effect size of the total sample in this study is -0.166 and its $95 \%$ confidence interval is $(-0.319,-0.01)$ does not include " 0 ", which indicates that the average effect size is notable. Many experiments on decisions neuroscience also shows that: emotion has a significant impact on rational person behavior. This is consistent with the current three mainstream theories, somatic marker theory [30], risk is emotion theory [31], the expected emotional theory [11], they both think emotion play an important role in rational person behavior. Moreover, from the view of magnetic nuclear resonance we find that the reason why rational person behavior mainly affected by the emotion is related with the prefrontal cortex, nucleus accumbens septum, insular, anterior cingulate, nucleus amygdalae and other brain regions activated on. For example, the activation of nucleus accumbens septum is related to rational person's approach behavior, the activation of insular is related to economic man's avoidance behavior oppositely. From the perspective of event-related potentials, emotion influence behavior is reflected in the differences in EEG-related component such as P2, P3, N2, ERN, MFN and FRN in volatility size. Meanwhile, the total sample $Q$ value (48.212) is significant which can been seen from Table $\mathbf{2}$, indicating the independent study is heterogeneity, there may be some potential regulated variables that affect the relationship of emotion and behavior.

\section{ANALYSIS OF REGULATION}

Because there is certain heterogeneity between each independent study, we need to explore their possible regulated variables. In the meta-analysis regulated variables come from the sample literature's code, and it can be divided into two categories, one is to measure the factors, and the other is external and internal factors at each institute, so we carefully read through the sample literature and summarized four regulated variables: emotional valence, emotional state, types of decisions and types were tested may regulate the influence of emotion to rational person behavior.

\subsection{Regulated Variables}

\subsubsection{Emotional Valence}

Emotional valence is a judge and weigh of all the feelings in a particular time, so it can be divided into three categories: positive, negative and neutral. For example, positive emotions like joy, excitement, etc. are all mean that we feel positive emotions and negative emotions are expressed as sadness, anger and other negative emotions, neutral emotions in between the positive and negative emotions, It can be also said no emotion in the middle of the state. Based on previous research, the different emotional valence will not produce the same effect on decision-makers' behavior $[32,33]$. In the positive emotion decision-makers are more confident, optimistic, cooperative [34], and it's often linked with the over- all processing of information [35]. However, in the negative emotions (such as sadness), decision-makers tend to exhibit low self-confidence and risk-aversion and take analytical process [36, 37]. In general, different emotional valence will affect the strength and direction of individual behavior.

\subsubsection{Emotional State}

According to the time and intention in the decisionmaking process, emotions can be divided into expected emotion and instant emotion [38]. The expected emotions mainly appear after the results of individual behavior, it's just a perception of future emotion and a predicted emotional state when individual facing the results of behavior. The instant emotion has nothing to do with the decision-making process itself. It's the motion that decision makers experience it actually so it's also named the decision-making process emotions. These two emotions effect the decision-making process in the different way may lead to certain differences on the influence of behavior.

\subsubsection{Types of Decisions}

In 2007, the University of Arizona's famous decision neuroscience scholar Professor Alan Sanfey published an article named "Decision Neuroscience: New Directions of Judgment and Decision-making Research" [39]. This article points out the decision neuroscience including two themes, the first is individual decision-making mechanisms research and the second is interaction of individual decision-makers among certain social situations. In addition, the study of risk decision-making is the most important areas of individual decision-making mechanism. Due to the different types of decisions, affecting strength and direction of emotion may be different in social decision-making and risk decisionmaking.

\subsubsection{Types Were Tested}

Experimental study of decision neuroscience perspective based on emotion and behavior, types were tested are divided into two categories, one is normal subjects, the other is a part of the brain injury associated with emotions were tested (brain injury subjects). Different types of subjects may have some impact on the relationship between emotion and behavior research. Therefore, it is necessary to test the regulated role of the type of test between the two.

\subsection{Regulated Effects of Test Results}

In order to examine the impact of potential regulated variables on emotion and individual decision-making behavior, we use regression analysis to study [40]. Firstly, encode the regulated variable which may affect the 30 effect values in the literature according to the form of variables $0-1$. Secondly, use the method of weighted least squares to determine whether all of the regulated variables exist. In the regression analysis, we serve each effect value as dependent variable and each potential regulated variable as independent variables, and use SPSS software to process the data, the results shown in Table 3.

From Table 3, we find that the regulatory role of emotional state, types of decision and types were tested on the relationship between emotions and rational person behavior 
Table 3. The result of regression analysis about the regulated variable.

\begin{tabular}{|c|c|c|c|}
\hline The Types of Regulated Variable & Number of Samples & Regression Coefficients $(\boldsymbol{\beta})$ & $\boldsymbol{p}$ Value \\
\hline \hline Emotional valence: Negative /Positive & $22 / 8$ & 0.546 & $0.003 *$ \\
\hline Emotional state: Instant emotions /Expected emotions & $13 / 17$ & -0.056 & 0.483 \\
\hline Types of decisions: Social decision-making/Risk decision-making & $13 / 17$ & -0.243 & 0.128 \\
\hline Types were tested: Normal /Brain Injury & $23 / 7$ & 0.188 & 0.382 \\
\hline Explained variance $R^{2}$ & & $37.1 \%$ & \\
\hline
\end{tabular}

Note: * indicates $p<0.05$, regression coefficients $(\beta)$ were standardized.

are not significant, but the emotional valence $(\beta=0.546$, $p<0.05$ ) has a significant positive regulatory role. Specifically, from the perspective of brain function orientation, positive emotion will cause striatum activation, leading rational person to take risk seeking behavior in risk decision making or cooperative behavior in social decision making, however, negative emotion such as disgust, fear, anxiety will cause the insular cortex activation, leading rational person to take risk averse behavior in risk decision making or non cooperative behavior in social decisions. From the perspective of brain electrical components, the influence of positive or negative emotions on rational person behavior are reflected in the amplitude differences of brain electrical components such as P2, P3, N2, ERN, MFN and FRN, but there is no consistent conclusion of amplitude change direction for various brain electrical components. Therefore, we should pay attention to the impact of emotional valence (both positive and negative emotions) on rational person behavior, and reasonable control emotion to make a more appropriate decision-making behavior.

The above four kinds of regulated variables explained $37.1 \%$ of the total variance. This not only explains that emotion impact on the rational person behavior is regulated by the regulated variable above on decision neuroscience perspective of selected literature, but also that there are other variables that affect the regulatory of the relationship between emotion and rational person behavior.

\section{CONCLUSION}

The meta-analysis on 30 effect values of sample literatures showed that the effect value between emotion and behavior is -0.166 , it's indicates that emotion significant impact on the rational person behavior $(p<0.05)$. Therefore, we should attach great importance to the emotion impact on behavior in social practices. Meanwhile, we make exploratory analysis by using regression analysis of potential factors which may regulate emotion effects on rational person behavior. The results show that the emotional valence has a significant regulatory role on the relationship between the two $(\mathrm{p}<0.05)$, among them, positive emotions can lead rational person to take risk seeking behavior in risk decision making or cooperative behavior in social decision making, however, negative emotions can lead rational person to take risk-averse behavior in risk decision making or non cooperative behavior in social decisions. From the perspective of event-related potentials, the influence of positive or negative emotions on rational person behavior are reflected in the amplitude differences of brain electrical components such as P2, P3, N2, ERN, MFN and FRN, but there is no consistent conclusion of amplitude change direction for various brain electrical components.

From the perspective of decision neuroscience, this paper carried out a systematic meta-analysis on many research findings which are exist inconsistency, and draw a universal conclusion between emotion and decision-making behavior. From an academic point of view, this paper verifies the influence of emotion on rational person behavior, finds more regulated variables which may affect the relationship between the two, and explores the deeper reasons. From a practical point of view, the result of meta-analysis in this paper provides a useful guidance to improve the quality and effectiveness of decision-making behavior in practice. It will improve the effectiveness of behavior if rational person know the emotion impact on behavior and successfully regulate their emotion. For example, in an emergency, government's behavior are risk appetite, at this time the media or government can induce the negative emotions of the public to prompt people take risky behavior in order to achieve the consistency of decision-making behavior between the public and the government and ensure better implementation results of decisions behavior.

Based on the means of decision neuroscience, there are some limitations of this paper, which are precisely future research focus. Firstly, from the perspective of decision neuroscience, emotion impact on the rational person behavior can explain $37.1 \%$ of the total variance, we need to further inquiry other potential regulated variables that may affect the relationship between the two; Secondly, this paper reveals the consistency conclusion of the relationship between emotion and behavior from many empirical research of decisions neuroscience by meta-analysis. We mainly research on the individual decision-making mechanism of rational person, but lack of research on the group decision-making mechanism or the relationship between emotion and interactive decision-making (such as game behavior), it cannot be ignored in the relationship between emotion and rational person behavior, and also worthy of future research.

\section{CONFLICT OF INTEREST}

The authors confirm that this article content has no conflict of interest. 


\section{ACKNOWLEDGEMENTS}

This work is supported by NSFC (No. 71173171) and Special Research of Shaanxi Provincial Department of Education (14JZ030).

\section{REFERENCES}

[1] R. B. Zajonc, "Feeling and thinking: Preferences need no inferences", American Psychologist, vol. 35, no. 2, pp. 151-175, 1980.

[2] T. D. Wilson, and J. W. Schooler, "Thinking too much: introspection can reduce the quality of preferences and decisions", Journal of Personality And Social Psychology, vol. 60, no. 2, pp. 181-192, 1991.

[3] A. Bechara, H. Damasio, D. Tranel, and A. R. Damasio, "Deciding advantageously before knowing the advantageous strategy", Science, vol. 275, no. 5304, pp. 1293-1295, 1997.

[4] J. S. Lerner, and D. Keltner, "Fear, anger, and risk", Journal of Personality and Social Psychology, vol. 81, no. 1, pp. 146-159, 2001.

[5] R. J. Dolan, "Emotion, cognition and behavior", Science, vol. 298, no. 5596, pp. 1191-1194, 2002

[6] M. G. Seo, and L. F. Barrett, "Being emotional during decision making-Good or bad? An empirical investigation", Academy of Management Journal, vol. 50, no. 4, pp. 923-940, 2007.

[7] Q. G. Ma, Q. Shen, and D. D. Li, "Chemical and genetic neural basis of economic decision making", Chinese Science Bulletin, vol. 55, no. 32, pp. 3089-3096, 2010.

[8] Q. G. Ma, and X. Y. Wang, "Cognitive neuroscience, economics and management nerve", Management World, vol. 10, no. 6, pp. 139-149, 2006.

[9] P. Wang, and L. J. Feng, "Element analysis review", Northwest Normal University (Social Science Edition), vol. 42, no. 5, pp. 5963, 2005.

[10] B. Shiv, G. Loewenstein, A. Bechara, H. Damasio, and A. R. Damasio, "Investment behavior and the negative side of emotion", Psychological Science, vol. 16, no. 6, pp. 435-439, 2005.

[11] B. Knutson, G. E. Wimmer, C. M. Kuhnen, and P. Winkielman, "Nucleus accumbens activation mediates the influence of reward cues on financial risk taking", Nerve Report, vol. 19, no. 5, pp. 509-513, 2008.

[12] L. C. Shu, "Uncertain decision-making mechanism of decisionmaking based on neuroscience", Zhejiang University, 2009.

[13] K. Wang, "Research Framework effect under emergency decision makers", Zhejiang University, 2010.

[14] J. L. Hall, "Affect risk taking, and financial decision: investigating the psychological and neural and neural mechanisms by which conscious affective processes influence decisions", The University of Michigan, 2010.

[15] M. P. Paulus, C. Rogalsky, A. Simmons, J. S. Feinstein, and M. B. Stein, "Increased activation in the right insula during risk-taking decision making is related to harm avoidance and neuroticism", Neuroimage, vol. 19, no. 4, pp. 1439-1448, 2003

[16] B. Shiv, G. Loewenstein, and A. Bechara, "The dark side of emotion in decision-making: When individuals with decreased emotional reactions make more advantageous decisions", Cognitive Brain Research, vol. 23, no. 1, pp. 85-92, 2005.

[17] G. Coricelli, H. D. Critchley, M. Joffily, J. P. Doherty, A. Sirigu, and R. J. Dolan, "Regret and its avoidance: a neuroimaging study of choice behavior", Nature Neuroscience, vol. 8, no. 9, pp. 1255$1262,2005$.

[18] S. W. Anderson, A. Bechara, H. Damasio, D. Tranel, and A. R. Damasio, "Impairment of social and moral behavior related to early damage in human prefrontal cortex", Nature Neuroscience, vol. 2, no. 11, pp. 1032-1037, 1999.
[19] M. A. Boksem, and D. De Cremer, "Fairness concerns predict medial frontal negativity amplitude in ultimatum bargaining", Social neuroscience, vol. 5, no. 1, pp. 118-128, 2010.

[20] A. G. Sanfey, J. K. Rilling, J. A. Aronson, L. E. Nystrom, and J. D. Cohen, "The neural basis of economic decision-making in the ultimatum game", Science, vol. 300, no. 5626, pp. 1755-1758, 2003.

[21] M. Koenigs, D. Tranel, "Irrational economic decision-making after ventromedial prefrontal damage: evidence from the Ultimatum Game", The Journal of Neuroscience, vol. 24, no. 4, pp. 951-956, 2007.

[22] D. Polezzi, I. Daum, and E. Rubaltelli, "Mentalizing in economic decision making", Behavior Brain Research, vol. 190, no. 28, pp 218-223, 2008

[23] T. Schreiner, J. Alexopoulos, and D. M. Pfabigan, "Facial cues affect the feedback negativity to offers in the ultimatum game. An EEG investigation", International Journal of Psychophysiology, vol. 77 , no. 3, pp. 337-340, 2010.

[24] J. Zhong, "Negative wave of cognitive neuroscience research faces the task of trust game affect the attractiveness of feedback", Southwestern University, 2009.

[25] J. Hewig, N. Kretschmer, R. H. Trippe, H. Hecht, M. G. Coles, C. B. Holroyd, and W. H. Miltner, "Why humans deviate from rational choice", Psychophysiology, vol. 48, no. 4, pp. 507-514, 2011.

[26] J. Wang, "Emotional impact cognitive and neural mechanisms of decision making process evaluation results", Tianjin University, 2012 .

[27] K. M. Harle, L. J. Chang, and M. Wout, "The neural mechanisms of affect infusion in social economic decision-making: A mediating role of the anterior insular", Nerve Image, vol. 61, no. 1, pp. 32-40, 2012.

[28] M. I. Tortosa, and M Ruz, "Race, emotion and trust: An ERP study", Brain Research, vol. 1494, no. 4, pp. 44-55, 2012.

[29] H. Zhao, and Y. Luo, "Transaction cost determinants and ownership-based entry mode choice: A meta-analytical review", Journal of International Business Studies, vol. 35, no. 6, pp. 524544, 2004.

[30] D. Antonio, "Descartes' error: Emotion, rationality and the human brain", New York: Putnam, 1994.

[31] G. F. Loewenstein, E. U. Hsee, and C. K. Risk, "As feelings", Psychological bulletin, vol. 127, no. 2, pp. 267-271, 2001

[32] J. P. Forgas, "Affective influences on attitudes and judgments", New York: Oxford University Press, 2003.

[33] Zajonc, and B. Robert, "Feelings and thinking: Closing the debate over the independence of affect", New York: University of Cambridge press, 2000.

[34] J. P. Forgas, G. H. Bower, and S. J. Moylan, "Praise or blame? Affective influences on attributions for achievement", Journal of Personality and Social Psychology, vol. 59, no. 4, pp. 809-812, 1990

[35] K. Gasper, "Do you see what I see? Affect and visual information processing", Cognition \& Emotion, vol. 4, no. 18, pp. 405-421, 2004.

[36] M. S. Clark, and A. M. Isen, "Understanding the relationship between feeling states and social behavior", Cognitive social psychology, vol. 6, no. 29, pp. 63-68, 1982.

[37] A. M. Isen, and K. A. Daubman, "The influence of affect on categorization", Journal of Personality \& Social Psychology, vol. 47, no. 6, pp. 1206-1217, 1984.

[38] G. Lowenstein, and J. S. Lerner, "Role of affect in decision making", Handbook of Affective Sciences, vol. 202, no. 2, pp. 3753, 2003.

[39] A. G. Sanfey, "Decision neuroscience: New directions in studies of judgment and decision making", Current Directions in Psychological Science, vol. 16, no. 3, pp. 151-155, 2007.

[40] D. B. Wilson, "Practical meta-analysis", Sage Publications Inc, 2000 .

Received: September 16,2014

Revised: December 23, 2014

Accepted: December 31, 2014

(C) Xiong et al; : Licensee Bentham Open.

This is an open access article licensed under the terms of the (https://creativecommons.org/licenses/by/4.0/legalcode), which permits unrestricted, noncommercial use, distribution and reproduction in any medium, provided the work is properly cited. 